\title{
"Relation between Organisational Citizenship Behavior, Workplace Spirituality and Job Performance in BFSI sector in India"
}

\author{
AUTHORS \\ Shaad Habeeb id https://orcid.org/0000-0002-5832-242X \\ R http://www.researcherid.com/rid/A-1424-2019
}

Shaad Habeeb (2019). Relation between Organisational Citizenship Behavior, ARTICLE INFO Workplace Spirituality and Job Performance in BFSI sector in India. Problems and Perspectives in Management, 17(1), 176-188. doi:10.21511/ppm.17(1).2019.16

DOI http://dx.doi.org/10.21511/ppm.17(1).2019.16

RELEASED ON

Wednesday, 06 March 2019

RECEIVED ON

Saturday, 26 January 2019

ACCEPTED ON

Tuesday, 26 February 2019

\section{(c) EY}

LICENSE

This work is licensed under a Creative Commons Attribution 4.0 International License

JOURNAL

"Problems and Perspectives in Management"

ISSN PRINT 1727-7051

ISSN ONLINE $1810-5467$

PUBLISHER

LLC "Consulting Publishing Company "Business Perspectives"

FOUNDER LLC "Consulting Publishing Company "Business Perspectives"

NUMBER OF REFERENCES

51
NUMBER OF FIGURES

1
NUMBER OF TABLES

6

(C) The author(s) 2022. This publication is an open access article. 


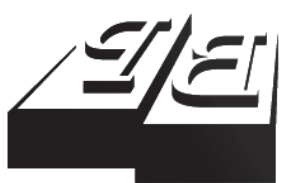

BUSINESS PERSPECTIVES

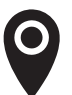

LLC "CPC "Business Perspectives" Hryhorii Skovoroda lane, 10, Sumy, 40022, Ukraine

www.businessperspectives.org

Received on: $26^{\text {th }}$ of January, 2019 Accepted on: 26 ${ }^{\text {th }}$ of February, 2019

(C) Shaad Habeeb, 2019

Shaad Habeeb, Ph.D., Assistant Professor, School of Management and Business Studies, Jamia Hamdard University, New Delhi, India.
RELATION BETWEEN

ORGANIZATIONAL CITIZENSHIP BEHAVIOR, WORKPLACE SPIRITUALITY AND JOB PERFORMANCE IN BFSI SECTOR IN INDIA

\begin{abstract}
Companies across the world are struggling to keep the employees engaged and retained to their work. Moreover, today's workforce is increasingly seeking intrinsic benefits beyond the material rewards of a job. In this context, this study aims to assess the relationship between organizational citizenship behavior (OCB), workplace spirituality (WS) and job performance (JP) in a non-Western setting where primary quantitative research was conducted in an Indian setting. The sector under study was Banking, Finance, and Insurance Services (BFSI), given retention issues since the financial crisis of 2008. A statistically evaluated sample of 433 respondents was utilized to attain the findings. Results revealed a statistically significant positive relationship between $\mathrm{OCB}$, WS and JP that was achieved through regression analysis. However, findings also showed that OCB is not a moderator between WS and JP. The gap in the research was addressed given the lack of studies determining the impact of OCB on individual job performance. Further, the impact was positively highlighted in the Indian context. The implications to the BFSI sector were made that required companies to promote a culture for voluntary work practices to enhance JP.
\end{abstract}

Keywords

mindfulness, transcendence, sportsmanship, conscientiousness, performance oriented behavior, Indian financial institutions, employee engagement, employee retention

JEL Classification D23, J24, M10, M12

\section{INTRODUCTION}

In the contemporary fast-paced business environment, the organizations are challenged to design and implement the workplace policies that enhance employee engagement. The employee engagement has been considered imperative for the individual performance of the employees in the workplace (Dajani, 2015). Without employee engagement, the organizations cannot attain the business strategy objectives that are vital for improving the organizational performance (Campbell \& Wiernik, 2015). Furthermore, workplace spirituality (WS) is one of the significant constructs in ensuring the employee motivation and engagement in the organizations as noted by previous researches, so it is important to determine the role of WS in the organization.

It is essential to focus on the WS given the changes in the work environment that have resulted in psychological challenges needed to focus on work. The academic studies in the past two decades have observed that there is turbulence in the psychological contract between the employee and the employer (Giacalone \& Jurkiewicz, 2003). As a result, 
some outcomes are reengineering, downsizing, and the emergence of new technologies (Giacalone \& Jurkiewicz, 2003). The need of workplace spirituality is therefore realized to address the disruption in the psychological contract and to encourage the meaning of workplace spirituality in the workplace at both the individual and the organizational level.

The organizations in the contemporary business environment are encountering challenges to operate in an uncertain competitive environment where companies strive to engage employees and retain them. Workplace spirituality is one of the means to engage employees while also fostering community. Particularly, the construct of workplace spirituality is to enable the employees to perform beyond their job roles, which tend to cultivate a positive change in the organization where the connection between workplace and employees is amplified. Therefore, it is important to focus on the spirituality of performance as it can promote employee engagement. In turn, increased employee engagement enhances the performance of employees while also influencing the overall organizational citizenship behavior.

\section{PROBLEM STATEMENT}

The earlier studies in a similar context have explored the relationship between workplace spirituality and employee performance. However, the gap is identified since there are no studies in non-eastern settings to determine the relationship between workplace spirituality and job performance. The interest in the study revolves around the notable gap where the concept of OCB is not considered to determine workplace spirituality and job performance. In the literature, Gull and Doh (2004) acknowledged that workplace spirituality is associated with higher levels of achievement regarding personal and organizational context. It is important to explore the concept since failure to develop a connection with the organizational life can lead to a loss in commitment, adversely influencing the job performances.

By focusing on workplace spirituality as a phenomenon under study, the research attempts to determine the chances that employers have to engage employees. Likewise, another purpose is to promote trust in the organization. Furthermore, workplace spirituality could also enhance confidence to increase the participation of employees in accomplishing the objectives of the organization. In addition, this use could also contribute to a higher level of community satisfaction that would be achieved due to organisational citizenship behavior. There is evidence where Creswell (2016) highlighted that meditation training is one of the techniques comprising self-transcendence, concentration, and mindfulness as integral components of spirituality to increase workplace spirituality. Then, it could be argued that workplace spirituality could be effective both physically and psychologically for the workplace and practising individuals

\section{OBJECTIVES OF THE STUDY}

Previous studies have focused on workplace spirituality. Here, the relationship with the employee performance is evaluated. Yet, there is a lack of evidence regarding the role of workplace spirituality on job performance and organizational citizenship behavior within a complex work environment. By conducting this research, organizations and scholars could be assisted in creating best practices and policies that nurture workplace spirituality. For instance, professionals could consider incorporating workplace spirituality in their organizational culture to engage employees. The concept of complex organizations refers to the organization that has two or more people who perform specialized tasks. Additionally, these individuals are under different management functions within multiple hierarchies to achieve the common goals of the organization.

The objective of the study is to evaluate the phenomenon in the context of Banking, Financial Services and Insurance (BFSI). The reason for choosing this sector is that these areas are experiencing negative growth after the global financial crisis of 2008. It has been illustrated in the report of Deloitte (2014) that the BFSI had encountered 
serious challenges post-financial crash and it is struggling with employee retention and performance. In addition, the reports also acknowledge the need to create interventions for BFSI sector to retain employees and increase performance. In this regard, the objective of the research is to evaluate the role of workplace spirituality on job performance and organizational citizenship behavior in the context of BFSI to determine whether it can be considered as an intervention to improve performance in the companies.

\section{LITERATURE REVIEW}

\subsection{Defining spirituality}

For understanding workplace spirituality one is required to define the concept of spirituality. This term defined by Guillory (2000) as a different phenomenon than religion, which nourishes the inner life of people. Likewise, Cash and Gray (2000) noted that religion is a broader concept that is far from spirituality, which comprises an association of organizational structure and specific rites and rigours. In addition, spirituality is considered as being derived from the inner consciousness that is beyond the learnt and taught belief systems. On the other hand, Thompson (2000) describes spirituality as including ethics, character, and awareness to give oneself for the benefit of others. It can also be claimed that religion is a framework to achieve spirituality.

\subsection{Defining workplace spirituality}

The concept of workplace spirituality is gaining momentum and is highlighted by scholars in academic research because of its association with employee engagement. Regarding workplace spirituality, there is a theoretical framework discussed in the literature, which identifies a number of factors associated with workplace spirituality. Petchsawang and Duchon (2009) identified four components of workplace spirituality that include mindfulness, meaningful work, transcendence, and compassion. The authors define workplace spirituality as a means to increase engagement through compassion towards others and developing an inner consciousness in the pursuit of meaningful work. Positive psychology researchers have examined the pursuit of meaning- ful work through a focus on mindfulness. In this context, Petchsawang and Duchon (2009) argued that meaningful work refers to the experience of an individual that their work is a significant and meaningful part of life. The similar argument has been portrayed by Duchon and Plowman (2005) who claim that an individual's work might have meaning beyond the material rewards and, ergo, would be considered as meaningful work.

Another characteristic of workplace spirituality is the mindfulness of work. In this case, Petchsawang and Duchon (2009) argued that meaningful work is produced by being mindful of inner and outside situations encountered by an individual. When the individuals are mindful, some tend to experience flow. According to Csikszentmihaly (1990), the flow occurs when a person is fully immersed in an activity where they lose track of time. The third component of workplace spirituality is transcendence. This term is defined by Pratt and Ashforth (2003) as a connection to something greater than oneself. When fostered in the organization within the organizational perspective, transcendence enables employees to be part of something larger than their individual input. As a result, these characteristics could enhance employee engagement.

The fourth component of workplace spirituality is compassion, which could be a feeling of care and support towards others. In the context of the organization, compassion has been defined by Lyubomirsky, Sheldon, and Schkade (2005) as engaging in the act of kindness to stimulate reciprocal relationships with co-workers. Consequently, compassion could lead to boosting the shortterm and long-term well-being of the workers (Lyubomirsky, Sheldon, \& Schkade, 2005). Thus, workplace spirituality is a strong foundation for achieving excellence in employee performance since it promotes an employee. Notably, the four core constructs of workplace spirituality provide a rationale for why workplace spirituality acts as a predictor of two-criteria organizational citizenship behavior and job performance.

\subsection{Organizational level WS}

WS in the literature has been evaluated at the individual, group, and organizational level and this section present the WS in the context of the or- 
ganization. For Gupta (2017), WS at the organizational level refers to the corporate feeling that is indicative of the work environment of the organization. Moreover, WS has been portrayed by other researchers as an organizational culture that facilitates the employee experience of transcendence and connectedness to produce a sense of completeness and joy (Petchsawang \& McLean, 2017; Giacalone \& Jurkiewicz, 2003). This definition by the researchers indicates an organization that creates and nurtures its environment through WS. It has also been argued by Vallabh and Singhal (2014) that spirituality is different among individuals. At the organizational level, this characteristic also applies to the organizations where there are different WS. Walt and Klerk (2014) argued that WS in the organization adheres in terms of benevolence, humanism, justice, mutuality, receptivity, trust, and generativist.

According to Lips-Wiersma and Mills (2014), the organizations with strong WS have a focus beyond capital returns where they focus on what is important and beneficial to the community and human beings. In addition, it has been proposed that organizations with WS have promoted intrinsic values among employees that maintain employee kindness, courage, and honesty. The literature also emphasizes on the four aspects of the WS where Saks (2011) illustrates that meaningful work, mastery, and competence, an aptitude to enjoy integrated life, and a positive symbiotic relationship are associated with the WS. Within the organization, Garg (2017) demonstrated that meaningfulness of work is associated with self-actualization and self-realization. Conversely, work meaningfulness could enable an employee to move beyond the physical and material pursuits of self-actualization. Together, the organizational level WS emerges as a means to promote meaningful practices where employees work beyond their responsibilities for the community and customers.

\subsection{Benefits of WS}

A number of researchers have highlighted the benefits of the WS in the literature. Garg (2017) presented the research results of the study by Moore and Casper (2006). The scholar argued that the benefits are realized at three levels, which include individual, societal, and organizational. The evi- dence of the benefits at the individual level has been pointed out by Sheng and Chen (2012) that include increased experience due to self-reflection, self-existence values, and enhancement in relationships between oneself, and the universe. In accordance with this finding, Pawar (2013) uncovered that WS is associated with a number of individual levels including physical, spiritual, emotional, social, ethical, and psychological. The findings of Pawar (2016) also revealed that people are peaceful in this working environment, while they also have similar feelings of others throughout the organization. In this context, Garg (2017) argued that WS has a positive impact on balanced decision making of an individual and work-life balance.

The evidence of the group level benefits of the WS has been revealed by Mumtaz (2017). For example, these findings suggested that strong team bonding is associated with individual development and growth (Mumtaz, 2017). Additionally, team bonding also reduces the negative emotions that lead to improved organizational performance (Mumtaz, 2017). A similar argument has been presented by Duchon and Plowman (2005) who have identified job motivation, involvement, high commitment, and reduced absenteeism as results of incorporating WS in the organization. Furthermore, WS increases performance through the achievement of team goals in a coherent manner (Duchon \& Plowman, 2005). The organizational level benefits of the WS have been studied in depth, and there are numerous pieces of evidence to support the positive impact of WS on organizational performance. The research conducted by Duchon and Plowman (2005) and Gupta, Kumar, and Singh (2014) have found reduced turnover and absenteeism in the organization. The researchers have also found improved communication, ethical behavior, workplace relationships, work engagement, job performance, and decision making as benefits at the organizational level (Altaf \& Awan, 2011; Rego \& Pina e Cunha, 2008; Krishnakumar \& Neck, 2002).

In the similar context, the research conducted by Sheng and Chen (2012) has also found that the organizations that develop WS and incorporate it in the workplace environment allow employees to devote themselves fully to perform the activities beyond the organizational responsibilities. This 
achievement could also make employees feel that they are part of the organization (Sheng \& Chen, 2012). The argument is consistent with Karakas (2010) who noted WS could be used as a means to promote organizational performance in terms of achieving organizational objectives and developing a sense of wellbeing among employees while also promoting interconnectedness. Garg (2017) also supported the argument adding that many of the organizations that adapt WS have realised engagement of employees with the organizational operations. The pieces of evidence reveal that there could be a positive impact of WS at the individual, group, and organizational level.

\subsection{WS - Indian context}

The reason for discussing WS in the context of India is based on the limited availability of research conducted on Indian BFSI companies. Yet, there has been a long tradition of practising WS in India given that religious practices and spirituality are preferably embedded in the culture. Garg (2017) identified that some considered that the duty of an individual in the Indian culture is to reflect spirituality. Pandey, Gupta, and Kumar (2016) developed the four constructs that are practised as spirituality in the workplace. The authors noted that the constructs include connecting people for wellbeing, developing a sense of authenticity, sense of community, and gratefulness (Pandey, Gupta, \& Kumar, 2016). Furthermore, it has been proposed that employees work meditatively, therefore, employees could become engaged with the organization. Consequently, the individuals could perform meaningful work that is for inner satisfaction instead of earning income. In this context, Pardasani, Sharma, and Bindlish (2014) argued that the WS practised in Indian context reflects the theory of Karma. This idea postulates that the good and bad of a person is attracted by his moral and immoral actions, respectively. The teachings of Karma could appeal employees to work meaningfully without expecting anything return as the action would result, inherently, in a good return.

The study in this context conducted on the banking company in India by Subramaniam and Panchanatham (2013) found a connection between WS and the core values of employees of the bank. The findings also entail that bank em- ployees have a sense of spiritual fulfilment, which enables them to align with the bank's values and create a spiritual workplace. The argument is also supported by Pardasani, Sharma, and Bindlish (2014) who claimed that there is an association between the Indian spiritual traditions and the dimensions of the WS. These dimensions include transcendence of self, interconnectedness, holistic growth, and alignment with the organizational values (Pardasani, Sharma, \& Bindlish, 2014). Further, some spiritual traditions were also identified by the authors. These traditions were passion and creation, goodness and preservation, and destruction and ignorance (Pardasani, Sharma, \& Bindlish, 2014). These aspects collectively lead to the fearless, calm, modest, pure, self-control, willingness to sacrifice, and to the prevention of envy and greed. In other words, WS is in the Indian workplace is practised given its embedment with religious and cultural tradition along with the evidence from the banking sector that also supports the findings.

\subsection{Defining organizational citizenship behavior}

The second concept that is utilized in the research article is the theory of Organizational Citizenship Behavior (OCB). The citizenship in the organizational context can be defined as an individual employee's behavior that is in association with the goals and policies of the organization. The initial time when the concept of OCB existed was in the works by Barnard in the 1930s. At this time, Barnard perceived these extra-role behaviors as the display of selfless and voluntary behavior of employees towards the achievement of organizational objectives.

The theoretical foundation of the OCB exists in the social exchange theory where the researchers explained the work behavior of the individual employees on the basis of trust. The findings indicate that an increase in trust would extend the goodwill among employees and co-workers (Blau, 1964). In addition, the trust could foster an environment of positive working relationship throughout the organization (Blau, 1964). Indeed, employees who had received positive experiences tend to reciprocate the feeling by contributing to the objectives of the organization. Furthermore, 
the concept of OCB is also defined by Veličkovska (2017) as an engagement of an individual regarding workplace responsibilities apart from the set of duties for which the employee is compensated by the organization. The OCB involves performing tasks without expectation of bonuses offered by the company while contributing to the achievement of organizational goals.

A similar statement has been offered by Organ (2005) regarding OCB. The author explains OCB as a discretionary behavior of an individual that is not explicitly recognized by a reward system of the organization, but it enhances the functioning of an organization. There are four components of OCB as highlighted by Organ (1988). These factors include altruism, civic virtue, conscientiousness, courtesy, and sportsmanship. Together, those elements benefit the organizations in manners that are not limited to an enriched organizational culture, but they are extended to the customers in the form of customer loyalty. It has also been evidenced by Armario, Castro, and Ruíz (2004) that OCB enhances the ability of employees to interact with the customers resulting in an increased quality of service and promotion of customer loyalty. In addition, OCB promotes the voluntary behavior of employees to engage in extra efforts that would contribute to the success of the organization or contribute to achieving the organizational goals.

\subsection{OCB dimensions outside Western culture}

According to Vaijayanthim, Shreenivasan, and Roy (2014), the concept of OCB differentiates from culture to culture, whereas there might be a few similar dimensions that are shared among the cultures. The study conducted in Taiwan by Farh, Earley, and Lin (1997) found five dimensions practised as OCB. The researchers found elements such as altruism, civic virtues, conscientiousness, protection of resources, and managing interpersonal harmony (Farh, Earley, \& Lin, 1997). However, in the context of the Western culture, three OCB dimensions were practised that include altruism, civic virtues, and conscientiousness, whereas the other two dimensions were not practised. The reason for not practising managing interpersonal harmony and protection of resources in the
Western organisations is because those OCB dimensions are embedded in the Asian culture that is different from Western culture. In this context, Gelfand et al. (2017) found that the dimensions of sportsmanship and courtesy are identified as job roles by the employees in workplaces in Japan and Hong Kong. The reason was that Asians are more concerned about society, whereas the concept was not the same in the US and Australia.

\subsection{OCB dimensions - Indian context}

The application of OCB in the Indian context has been evidenced by Gupta and Singh (2012) in the business company of India where they found sportsmanship, courtesy, civic virtue, altruism and compliance as the model of OCB. The findings further stated that the model is not formally implemented in the business environment. Rather, the three dimensions are practised in the organization. Particularly, those dimensions include punctuality, organization orientation, and individual orientation. The organization orientation is associated with civic virtue, sportsmanship, and helping, whereas punctuality refers to the adherence of the work schedule in the organization (Gupta \& Singh, 2012). The individual orientation is practised in terms of courtesy. In this context, Vaijayanthi, Shreenivasan, and Roy (2014) conducted a study to explore the relationship between job satisfaction and OCB in the Indian setting. In this regard, the researchers found that there are four dimensions of OCB that are practised in India except for sportsmanship (Vaijayanthi, Shreenivasan, \& Roy, 2014). In contrast, the findings of Shankar (2016) revealed that all the five dimensions including sportsmanship are practised by the Indian workforce.

\subsection{Hypotheses development}

There are three constructs discussed in the literature that have a multi-dimensional relationship. However, there is a gap in the literature where all the three constructs are not evaluated in the study. Particularly, the literature reveals that there are different elements of WS being practised in workplaces, which benefit at the individual and organizational level (Garg, 2017; Krishnakumar \& Neck, 2002), whereas in places were OCB is practised there are benefits to the organization (Garg, 2017; Krishnakumar \& Neck, 2002). Moreover, the limi- 


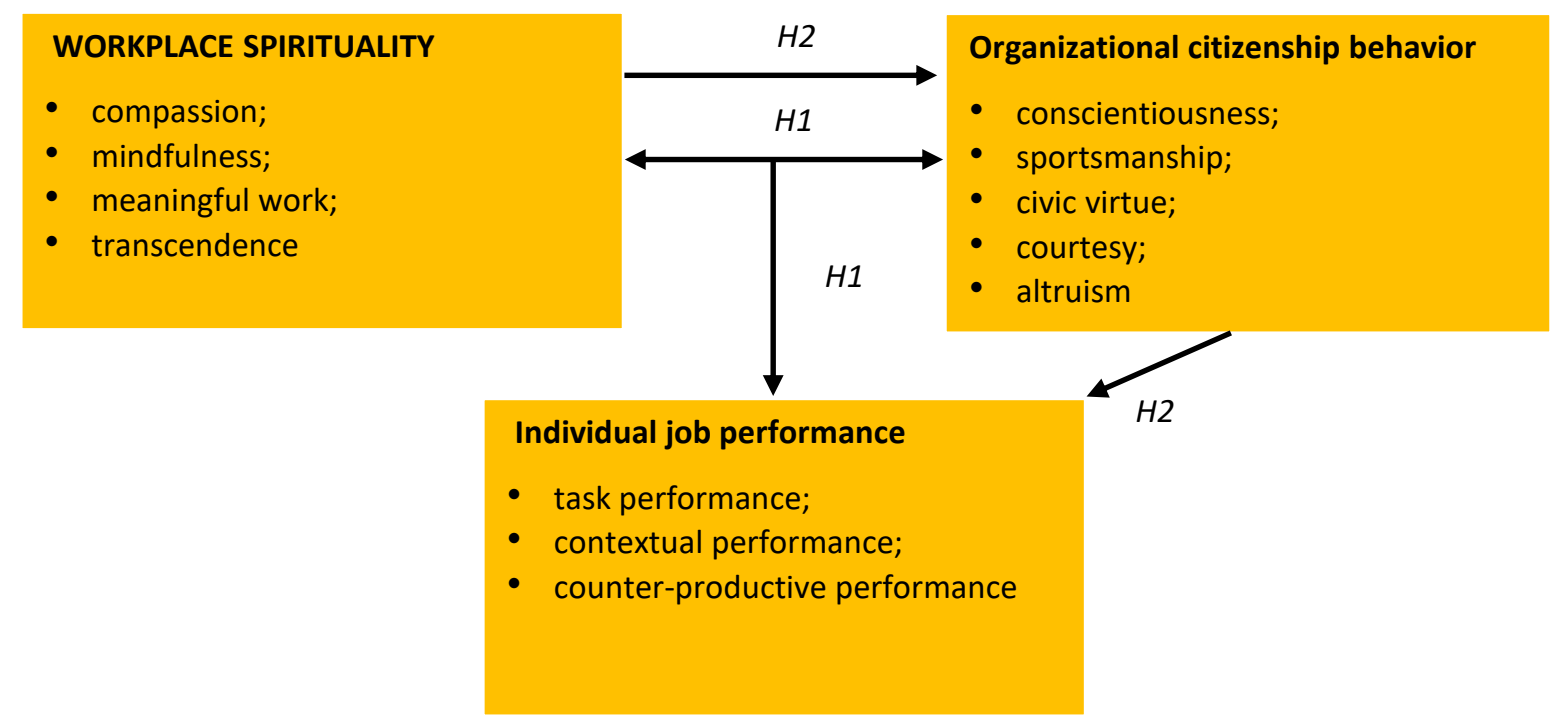

Figure 1. Conceptual framework of WS, OCB and IJP

tation of determining whether OCB influences individual job performance (IJP) needs to be evaluated. Furthermore, the Indian context presents a peculiar situation on the conceptualization of the three constructs (WS, JP, and OCB) given differences in culture. Hence, these differences could be based on the unique behaviors linked with those dimensions of the three constructs, which, at face value, seem similar (Bakhshi, Kumar, \& Kumari, 2009). Thus, there is a gap in knowledge on the relationship between WS and the contextual aspect of JP. The concept of JP has also been defined as OCB in a situation where OCB extends beyond on-the-job relationships and where constructs that go by the same label actually represent different behaviors (Bakhshi et al., 2009). This study separates OCB from JP by conceptualizing it as a separate concept with its own specific dimensions. As such, the distinction could allow for the evaluation of distinct relationship with WS and with JP, but which together with WS affects JP. The researcher has not come across any study, especially in the Indian context, that adopted such an integrative approach to the three. In this regard, the proposed hypotheses of the study are presented below that interrogates the WS, OCB, and JP relationship, whereas a moderating relationship of OCB would also be evaluated.

\section{H1: $\quad$ There is a significant positive impact of $O C B$ and WS on JP.}

H2: $\quad$ There is a moderating role of OCB between WS and JP.

\section{METHODOLOGY}

\subsection{Research design}

This study encompassed the use of a descriptive research design, which sought to analyse the impacts of WS through the interaction of the observant with the natural or unaltered environment. This approach provides an opportunity for the identification of specific, measurable variables that can be studied further or can be assessed from previous conclusion points (Twill \& Buckhesiter, 2009). The descriptive approach of analysing situations is sufficient as it provides an opportunity for the researcher to capture a significant amount of information (Kim, Sefcik, \& Bradway, 2016). One of the core advantages in using the quantitative approach in the study is the efficiency of the technique since the results can be gathered, combined, assessed, and compressed to form a conclusion in a short-time span. Moreover, the quantitative approach provides an opportunity for the respondents in the BFSI sector to deliver precise responses, as well as save time in the collection of individual responses. The conceptual framework is depicted in Figure 1.

\subsection{Sampling technique}

This study used purposive sampling along with a non-probability sampling technique as the technique of selecting samples. Since the researcher has defined the criteria for sample inclusion, only 
volunteers who were deemed eligible were included in the study. Based on this method, the companies selected for the study were two banks and four insurance companies. One of the banks is private, and the other is public. There are two public sector insurance enterprises and two private sector insurance enterprises. Regarding the selection criteria, the employees selected as respondents were on the permanent and on-roll basis and had been in the firm for at least one year to ensure a higher level of accuracy in the responses. Participants were those who were willing to participate and who completed the entire questionnaire.

\subsection{Sample size and data collection}

A total of 500 questionnaires were circulated across the different organizations, and 470 filled questionnaires were returned. Among the ones returned, 37 were found redundant and were discarded. The final sample size was 433 . The researcher used a four-part questionnaire for conducting the survey. The first part included the demographic variables, and in the other, three were an adaptation of pre-validated tools on the three main variables of the study, i.e., WS, OCB, and JP. To collect the data, the questionnaire was physically distributed to the respondents and were collected later.

\section{RESULTS AND FINDINGS}

Data analysis was conducted to determine the relationship between the three constructs as identified in the conceptual framework illustrated in
Figure 1. These constructs were workplace spirituality (WS), organizational citizenship behavior (OCB) and job performance (JP).

\subsection{Evaluating first hypothesis}

The regression analysis was conducted via the application of an ANOVA test to determine the impact of workplace spirituality (WS) and organizational citizenship behavior (OCB) on job performance (JP) to determine the first hypothesis. The results of the analysis are presented in Table 1 . The findings demonstrate the significance of the model, whereas Table 2 illustrates the model summary of the impact of WS and OCB on JP.

The model summary presented in Table 2 shows $R$, $R^{2}$ and adjusted $R^{2}$ after entry of the independent variables. The value of $R$ was statistically significant from zero. From the results, it can be said that there is a variance of $53 \%\left(R^{2}=0.53\right)$ in individual job performance.

The results of the current study uncovered a statistically significant effect of workplace spirituality and organizational citizenship behavior on individual job performance. In addition, the beta values showed that both of the predictors made a statistically significant contribution to explaining job performance scores of the participant as presented in Table 3. The results also indicate that workplace spirituality is statistically significant to explain job performance (standardized beta $=0.28$; $p<0.005)$ and organizational citizenship behavior was statistically significant to the model (standardized beta $=0.51 ; p<0.005)$ (Table 3).

Table 1. ANOVA results of WS and OCB on JP

\begin{tabular}{|c|c|c|c|c|c|c|}
\hline & Model & Sum of squares & df & Mean square & $F$ & Sig. \\
\hline \multirow{3}{*}{1} & Regression & 44.30 & 1 & 22.15 & 247.83 & $.00^{\mathrm{b}}$ \\
\hline & Residual & 38.43 & 431 & .09 & - & - \\
\hline & Total & 82.73 & 432 & - & - & - \\
\hline
\end{tabular}

Note: Dependent variable: Job_Performance. Predictors: (Constant), Workplace_Spirituality, Org_Citiz_Beh.

Table 2. Model summary of the impact of WS and OCB on JP

\begin{tabular}{|c|c|c|c|c|c|c|c|c|}
\hline \multirow[b]{2}{*}{ Model } & \multirow[b]{2}{*}{$\boldsymbol{R}$} & \multirow[b]{2}{*}{$R$-square } & \multirow[b]{2}{*}{ Adjusted $R$-square } & \multicolumn{5}{|c|}{ Change statistics } \\
\hline & & & & $\begin{array}{c}R \text {-square } \\
\text { change }\end{array}$ & $F$ change & df1 & df2 & $\begin{array}{c}\text { Sig. } F \\
\text { change }\end{array}$ \\
\hline 1 & $.73^{\mathrm{a}}$ & .53 & .53 & .53 & 247.83 & 2 & 430 & .00 \\
\hline
\end{tabular}

Note: Predictors: (Constant), Workplace_Spirituality, Org_Citiz_Beh. 
Table 3. Coefficients of OCB and WS as independent variables

\begin{tabular}{|c|c|c|c|c|c|c|}
\hline & \multirow{2}{*}{ Model } & \multicolumn{2}{|c|}{$\begin{array}{c}\text { Unstandardized } \\
\text { coefficients }\end{array}$} & \multirow{2}{*}{$\begin{array}{c}\begin{array}{c}\text { Standardized } \\
\text { coefficients }\end{array} \\
\text { Beta } \\
\end{array}$} & \multirow[t]{2}{*}{$t$} & \multirow{2}{*}{ Sig. } \\
\hline & & $B$ & Std. error & & & \\
\hline \multirow{3}{*}{1} & (Constant) & .442 & .170 & - & 2.605 & .01 \\
\hline & Org_Citiz_Beh & .600 & .053 & .513 & 11.308 & .00 \\
\hline & Workplace_spirituality & .294 & .048 & .277 & 6.093 & .00 \\
\hline
\end{tabular}

Note: Dependent variable: Job_Performance

The pattern of results suggests that slightly more than half of the variability in individual work performance is predicted by WS and OCB of the employees. This finding supports previous research that OCB is related to job performance. Thus, the first hypothesis $(\mathrm{H} 1)$ is accepted, which states there is a positive effect of OCB and WS on the job performance.

A study of BFSI employees in Iran conducted by Rastgar et al. (2012) found that workplace spirituality had a significant positive influence on organizational citizenship behavior and job performance. In addition, WS and organizational citizenship behavior had a significant positive influence on employees' job performance.

\subsection{Evaluating second hypothesis}

Regression analysis was also conducted for ANOVA results to evaluate the second hypothesis that is the role of organizational citizenship behavior as a moderator between WS and JP. To test the moderating role, the WS was added to the model to explain individual participant's work performance scores. Subsequently, the interaction term and moderator variable were added to the model in order to test the impact of the interaction term.

The results of both the models in evaluating the moderating role of $\mathrm{OCB}$ is evaluated as illustrated in Table 4. The scores of organizational citizenship behavior and workplace spirituality were multiplied to generate interaction term. The findings of the ANOVA test of the two models presented findings for model 1; WS is the predictor of $J P$ and the model is significant $[F(1.431)=284.15$; $p<0.0005]$.

In addition, there is $40 \%$ of the variance in the individual work performance where $R^{2}=0.397$ as illustrated in Table 6. On the other hand, there was no statistically significant role of $\mathrm{OCB}$ between WS and JP [standardized beta $=-.20$; $p>.05]$. The second model showed the significance $[F(3,429)=164.97 ; p<0.0005]$, whereas the interaction term was not able to explain the JP uniquely. Collectively, the results evidence that OCB is not a moderator between WS and JP, whereas only WS can be considered as a predictor for JP; therefore, $H 2$ was rejected.

The results from the analysis suggest that to increase the performance of the employees, an increase of the contextual performance, task performance and productive work is required. Further, it could be necessary to increase the organizational citizenship behavior and promote workplace spirituality. In summary, the findings the organizations need to ensure that the employees are exposed to the practices promote the performance that is based on not sole-

Table 4. ANOVA results of 2 models for the moderator role of organizational citizenship behavior

\begin{tabular}{|c|c|c|c|c|c|c|}
\hline & Model & Sum of squares & df & Mean square & $F$ & Sig. \\
\hline \multirow{3}{*}{1} & Regression & 32.87 & 1 & 32.87 & 284.15 & $.00^{b}$ \\
\hline & Residual & 49.86 & 431 & .12 & - & - \\
\hline & Total & 82.73 & 432 & - & - & - \\
\hline \multirow{3}{*}{2} & Regression & 44.32 & 3 & 14.77 & 164.97 & $.00^{\circ}$ \\
\hline & Residual & 38.41 & 429 & .09 & - & - \\
\hline & Total & 82.73 & 432 & - & - & - \\
\hline
\end{tabular}

Note: Dependent variable: Job_Performance. Predictors: (Constant), Workplace_Spirituality. Predictors: (Constant), Workplace_ Spirituality, Org_Citiz_Beh, Interaction_term. 
Table 5. Coefficients of workplace spirituality, organizational citizenship behavior and interaction term

\begin{tabular}{|c|c|c|c|c|c|c|}
\hline \multirow{2}{*}{\multicolumn{2}{|c|}{ Model }} & \multicolumn{2}{|c|}{ Unstandardized coefficients } & \multirow{2}{*}{$\begin{array}{c}\begin{array}{c}\text { Standardized } \\
\text { coefficients }\end{array} \\
\text { Beta } \\
\end{array}$} & \multirow[t]{2}{*}{$t$} & \multirow{2}{*}{ Sig. } \\
\hline & & B & Std. error & & & \\
\hline \multirow{2}{*}{1} & (Constant) & 1.368 & .169 & - & 8.088 & .000 \\
\hline & Workplace_spirituality & .671 & .040 & .630 & 16.857 & .000 \\
\hline \multirow{4}{*}{2} & (Constant) & -.052 & 1.136 & - & -.046 & .963 \\
\hline & Workplace_spirituality & .415 & .279 & .390 & 1.490 & .137 \\
\hline & Org_Citiz_Beh & .721 & .281 & .617 & 2.565 & .011 \\
\hline & Interaction_term & -.029 & .067 & -.200 & -.440 & .660 \\
\hline
\end{tabular}

Note: Dependent variable: Job_Performance.

Table 6. Model summary of moderator effect of organizational citizenship behavior

\begin{tabular}{c|c|c|c|c|c|c|c|c}
\hline \multirow{2}{*}{ Model } & \multirow{2}{*}{$\mathbf{R}$} & $\boldsymbol{R}$-square & \multirow{2}{*}{$\begin{array}{c}\text { Adjusted } \\
\boldsymbol{R} \text {-square }\end{array}$} & $\begin{array}{c}\text { R-square } \\
\text { change }\end{array}$ & $\boldsymbol{F}$-change & df1 & df2 & $\begin{array}{c}\text { Sig. } \boldsymbol{F} \\
\text { change }\end{array}$ \\
\hline 1 & $.63^{\mathrm{a}}$ & .40 & .40 & .397 & 284.153 & 1 & 431 & .00 \\
\hline 2 & $.73^{\mathrm{b}}$ & .54 & .53 & .138 & 63.910 & 2 & 429 & .00 \\
\hline
\end{tabular}

Note: Predictors: (Constant), Workplace_Spirituality. Predictors: (Constant), Workplace_Spirituality, Org_Citiz_Beh, Interaction_term.

ly non-compensated responsibilities, but those that are voluntary. In such way, the employees tend to participate voluntarily and support the organizational functions of both the social and professional nature. This type of work could lead employees to perform insightful, meaningful, and considerate behaviors while also preventing job-related issues for colleagues and co-workers. Finally, it can also be said that the employees should be exposed to a workplace culture that is flexible for workplace spirituality where individuals tolerate inconvenience, support others with compassionate behavior, and have inward awareness. This type of exposure could lead to the perception of significant work as a means to realize transcendence.

Furthermore, most of the study's findings were associated with the literature arguments in the
Indian context where workplace spirituality was significant to job performance (Garg, 2017; Krishnakumar \& Neck, 2002). The impact of OCB on job performance was unknown, and this research also explained that there is a significant positive impact of OCB on the job performance of employees. It was also found that workplace spirituality is the moderator for individual job performance, but OCB cannot predict so there is no moderating role of OCB between WS and JP. More importantly, it was found that the WS observed in the context of India was explained by Pandey, Gupta, and Kumar (2016), as well as supported by Pardasani, Sharma, and Bindlish (2014). This congruency was attributed given that the dimensions of WS are practised in the context of India, because it is embedded in the culture as explained by Garg (2017) in the literature.

\section{CONCLUSION}

This research was conducted to evaluate the effect of organizational citizenship behavior and workplace spirituality on job performance in the BFSI sector of India, because there is a lack of research in the non-Western setting. The effective sample of the study was 433 respondents through purposive sampling technique. The theoretical foundations were utilized to understand the constructs and to design the research questionnaire for data collection. The literature provided evidence that there is a positive impact of workplace spirituality on the performance of individual and organization. The impact of WS 
and OCB was evaluated on JP, which was evaluated as the first hypothesis. The findings were obtained using regression analysis that showed a significant positive relationship between of OCB and WS on JP and $\mathrm{H} 1$ was accepted. The role of OCB as a moderator was also evaluated, but it was found that OCB does not perform as a moderator between WS and JP so $\mathrm{H} 2$ was rejected. The findings can be applied to the BFSI sector to promote a workplace culture for increasing WS by exposing employees to voluntary activities, as it would improve individual performance and organizational performance.

Though the findings of the study are robust and address the gap in the literature, there are certain weaknesses and limitations in the study. Firstly, the employees who participated in the research were not agreeing to disclose their positions. Further, the participants also did not want to discuss any of the organizational aspects to support the qualitative findings. Therefore, the lack of qualitative findings could address the issue of bias that otherwise can be observed due to socially desirable responses. Since there was limited research on the relationship between organizational citizenship behavior and individual performance, future studies of a qualitative nature could be focused on this context. In addition, future research might utilize instruments in a different setting to increase the generalizability of the findings.

\section{REFERENCES}

1. Altaf, A., \& Awan, M. A. (2011). Moderating effect of workplace spirituality on the relationship of job overload and job satisfaction. Journal of Business Ethics, 104(1), 93-99. Retrieved from https:// link.springer.com/article/10.1007/ s10551-011-0891-0

2. Armario, E. M., Castro, C. B., Ruz, D. M. (2004). The influence of employee organisational citizenship behaviour on customer loyalty. International Journal of Service Industry Management, 15(1), 27-53. https://doi. org/10.1108/09564230410523321

3. Bakhshi, A., Kumar, K., \& Kumari, A. (2009). National culture and organisational citizenship behaviour: Development of a scale. Organisation Behaviour. New Delhi: Global Publishing House. Retrieved from https://www.researchgate.net/ publication/251279726_National_ Culture_and_Organizational_ Citizenship_Behavior_ Development_of_a_Scale

4. Blau, P. M. (1964). Exchange and power in social life. New York, NY: J. Wiley. Retrieved from https:// books.google.com.ua/books/ about/Exchange_and_Power_in Social_Life.html?id=qhOMLscXZYC\&redir_esc $=y$

5. Briggs, S. R., \& Cheek, J. M. (1986). The role of factor analysis in the development and evaluation of personality scales. Journal of Personality, 54(1), 106-148. https://doi. org/10.1111/j.1467-6494.1986. tb00391.x

6. Campbell, J. P. (1990). The role of theory in industrial and organisational psychology. Retrieved from https://www. researchgate.net/publication/232439855_The_role_of_theory_in_industrial_and_organizational_psychology

7. Dunnette, \& Hough, L. M. (Eds.). Handbook of Industrial and Organisational Psychology (pp. 3973). Palo Alto, CA: Consulting Psychologists Press.

8. Duchon, D., \& Plowman, D. A. (2005). Nurturing the spirit at work: Impact on work unit performance. The Leadership Quarterly, 16(5), 807-833. https://doi.org/10.1016/j. leaqua.2005.07.008

9. Campbell, J. P., \& Wiernik, B. M. (2015). The modelling and assessment of work performance. Annual Review of Organisational Psychology and Organisational Behaviour, 2(1), 47-74. Retrieved from https://www.annualreviews. org/doi/10.1146/annurev-orgpsych-032414-111427

10. Cash, K. C., \& Gray, G. R. (2000). A framework for accommodating religion and spirituality in the workplace. Academy of Management Perspectives, 14(3), 124-134. Retrieved from https://www.jstor.org/ stable/4165665?seq=1\#page_scan_ tab_contents

11. Chattopadhyay, U., \& Bhawsar, P. (2017). Effects of Changing Business Environment on Organisation Performance: The Case of HMT Watches Ltd. South Asian Journal of Business and Management Cases, 6(1), 36-46. https://doi. org/10.4135/9781526441102

12. Creswell, J. D. (2016). Mindfulness Interventions. Annual Review of Psychology, 68(1), 491-516. https://doi.org/10.1146/annurevpsych-042716-051139

13. Csikszentmihalyi, M. (1990). Flow: The Psychology of Optimal Experience. New York, NY: Harper and Row.

14. Dajani, M. A. Z. (2015). The impact of employee engagement on job performance and organisational commitment in the Egyptian banking sector. Journal of Business and Management Sciences, 3(5), 138-147. http:// pubs.sciepub.com/jbms/3/5/1/ index.html

15. Deloitte (2014). Global Report. Deloitte Official Website. Retrieved 
from https://www2.deloitte.com/ tt/en/pages/about-deloitte/topics/ global-report-2014.html (accessed on January, 8, 2019).

16. Farh, J. L., Earley, P. C., \& Lin, S. C. (1997). Impetus for action: A cultural analysis of justice and organisational citizenship behaviour in Chinese society. Administrative Science Quarterly, 42(3), 421-444. https://doi. org/10.2307/2393733

17. Garg, N. (2017). Workplace spirituality and employee wellbeing: an empirical exploration. Journal of Human Values, 23(5), 129-147. http://dx.doi. org/10.1177/0971685816689741

18. Gelfand, M. J., Aycan, Z., Erez, M., \& Leung, K. (2017). Crosscultural industrial-organisational psychology and organisational behaviour: A hundred-year journey. Journal of Applied Psychology, 102(3), 514-529. https:// doi.org/10.1037/apl0000186

19. Giacalone, R. A., \& Jurkiewicz, C. L. (Eds.). (2003). Toward a science of workplace spirituality. In The handbook of workplace spirituality and organisational performance (pp. 3-28). Armonk, ME: Sharpe.

20. Guillory, W. A. (2000). The living organisation: spirituality in the workplace. Innovations International Inc. Salt Lake City: UT.

21. Gull, G. J. A., \& Doh, J. (2004). The "Transmutation" of the Organisation: Toward a More Spiritual Workplace. Journal of Management Inquiry, 13(2), 128-139. http://dx.doi. org/10.1177/1056492604265218

22. Gupta, M., Kumar, V., \& Singh, M. (2014). Creating satisfied employees through workplace spirituality: A study of the private insurance sector in Punjab (India). Journal of Business Ethics, 122(1), 79-88. Retrieved from https:// link.springer.com/article/10.1007/ s10551-013-1756-5

23. Gupta, V., \& Singh, S. (2012). Empirical evaluation of the dimensionality of organisational citizenship behaviour for Indian business context. Psychological Studies, 57(4), 392-403.
24. Karakas, F. (2010). Spirituality and performance in organisations: a literature review. Journal of Business Ethics, 94(1), 89-106. Retrieved from https://link. springer.com/article/10.1007/ s10551-009-0251-5

25. Kim, H., Sefcik, J., \& Bradway, C. (2016). Characteristics of Qualitative Descriptive Studies: A Systematic Review. Research in Nursing \& Health, 40(1), 23-42. https://doi.org/10.1002/nur.21768

26. Krishnakumar, S., \& Neck, C. P. (2002). The "what", "why" and "how" of spirituality in the workplace. Journal of Managerial Psychology, 17(3), 153-164. https://doi. org/10.1108/02683940210423060

27. Lips-Wiersma, M., \& Mills, A. J. (2014). Understanding the basic assumptions about human nature in workplace spirituality: Beyond the critical versus positive divide. Journal of Management Inquiry, 23(2), 148-161. https://doi.org/10.1177\%2F1056492613501227

28. Lyubomirsky, S., Sheldon, K. M., \& Schkade, D. (2005). Pursuing happiness: The architecture of sustainable change. Review of General Psychology, 9(2), 111-131. Retrieved from https://psycnet.apa. org/doi/10.1037/1089-2680.9.2.111

29. Moore, T. W., \& Casper, W. J. (2006). An examination of proxy measures of workplace spirituality: A profile model of multidimensional constructs. Journal of Leadership \& Organisational Studies, 12(4), 109-118. https://doi.org/10.1177\% 2F107179190601200407

30. Mumtaz, S. (2017). A systematic review of the framework of workplace spirituality: Current theoretical perspectives and changing trends. Asian Management Research Journal, 2(3), 143-167. Retrieved from https://www.researchgate.net/ publication/325312366_Systematic_review_on_framework_of_ Workplace_Spirituality_Current_theoretical_perspectives_and_ changing_trends

31. Organ, D. (1988). Issues in organisation and management series. Organisational citizenship behaviour: The good soldier syndrome. Lexington, MA, England: Lexington Books.

32. Organ, D. (2005). Organisational Citizenship Behaviour: Recent Trends and Developments. Annual Review of Organisational Psychology and Organisational Behaviour, 5, 295-306. http:// dx.doi.org/10.1146/annurevorgpsych-032117-104536

33. Pandey, A., Gupta, R. K., \& Kumar, P. (2016). Spiritual climate and its impact on learning in teams in business organisations. Global Business Review, 17(3), 159-172. https://doi.org/10.1177\%2F0972150916631208

34. Pardasani, R., R. Sharma, R., \& Bindlish, P. (2014). Facilitating workplace spirituality: Lessons from Indian spiritual traditions. Journal of Management Development, 33(8/9), 847-859. https://doi.org/10.1108/JMD-072013-0096

35. Pawar, B. S. (2013). A proposed model of organisational behaviour aspects for employee performance and well-being. Applied Research in Quality of Life, 8(3), 339-359. Retrieved from https://link. springer.com/article/10.1007/ s11482-012-9193-7

36. Pawar, B. S. (2016). Workplace spirituality and employee wellbeing: An empirical examination. Employee Relations, 38(6), 975-994. https://doi.org/10.1108/ER-112015-0215

37. Petchsawang, P., \& McLean, G. N. (2017). Workplace spirituality, mindfulness meditation, and work engagement. Journal of Management, Spirituality \& Religion, 14(3), 216-244. https:// doi.org/10.1080/14766086.2017.1 291360

38. Petchsawanga, P., \& Duchon, D. (2009). Measuring workplace spirituality in an Asian context. Management Department Faculty Publications, 12(4), 459-468. Retrieved from https://www. semanticscholar.org/paper/ Measuring-workplace-spiritualityin-an-Asian-Petchsawang-Duchon /23090ef4a3dcd4e305b262ccbd68 4f97e724d633 
39. Pratt, M. G., \& Ashforth, B. E. (2003). Fostering meaningfulness in working and at work. In K. Cameron, J. E. Dutton \& R. E. Quinn (Eds.), Positive organisational scholarship: Foundations of a new discipline (pp. 308-327). San Francisco, CA: Berrett- Koehler.

40. Rastgar, A. A., Zarei, A., Davoudi, S. M. M., \& Fartash, K. (2012) The link between workplace spirituality, organisational citizenship behaviour and job performance in Iran. ArthPrabhand: A Journal of Economics and Management, 1(6), 51-67.

41. Rego, A., \& Pina e Cunha, M. (2008). Workplace spirituality and organisational commitment: an empirical study. Journal of Organisational Change Management, 21(1), 53-75. https://doi. org/10.1108/09534810810847039

42. Saks, A. M. (2011). Workplace spirituality and employee engagement. Journal of Management, Spirituality \& Religion, 8(4), 317-340. http:// dx.doi.org/10.1080/14766086.201 1.630170

43. Shanker, M. (2016) Organisational Citizenship
Behavior and Organisational Commitment in Indian Workforce. Journal of Psychosocial Research, 11(2), 397-408. Retrieved from https:// www.questia.com/library/ journal/1P3-4313929721/ organizational-citizenshipbehavior-and-organizational

44. Sheng, C. W., \& Chen, M. C. (2012). Workplace spirituality scale design-The view of oriental culture. Business and Management Research, 1(4), 46. https://doi. org/10.5430/bmr.vln4p46

45. Subramaniam, M., \& Panchanatham, N. (2013). A Study of Spirituality in a Public Sector Bank in India. International Journal of Advances in Management and Economics, 2(4), 102-113. Retrieved from http://www.managementjournal. info/index.php/IJAME/article/ view/290

46. Thompson, C. M. (2000). The congruent life: Following the inward path to fulfilling work and inspired leadership. San Francisco, CA: Jossey-Bass.

47. Twill, S., \& Buckheister, N. (2009). A Descriptive Research Study of Economic Human Rights Violations in America.
Journal of Poverty, 13(4),

365-383. https://doi.

org/10.1080/10875540903272314

48. Vaijayanthi, P., Shreenivasan, K A., \& Roy, R. (2014). Deducting the organisational citizenship behaviour dimensions and its antecedent (job satisfaction) in the Indian context. Research Journal of Applied Sciences, Engineering, and Technology, 7(10), 19531960. http://dx.doi.org/10.19026/ rjaset.7.487

49. Vallabh, P., \& Singhal, M. (2014). Workplace spirituality facilitation: A person organisation fit approach. Journal of Human Values, 20(2), 193-207. https://doi.org/10.1177\%2F0971685814539407

50. Van der Walt, F., \& de Klerk, J. J. (2014). Workplace spirituality and job satisfaction. International Review of Psychiatry, 26(3), 379389. https://doi.org/10.3109/09540 261.2014.908826

51. Veličkovska, I. (2017). Organisational Citizenship Behaviour-Definition, Determinants and effects. Engineering Management, 3(1), 40-51. Retrieved from https:// menadzment.tfbor.bg.ac.rs/ english/wp-content/uploads/ sites/2/2017/02/3_1_40-51.pdf 